\title{
Risk Assessment of Chemical Contaminants Ingestion with Nutrition of Children Aged 3-6 Years from the City of Kazan ${ }^{+}$
}

\author{
Suryana Fomina *, Nataliya Stepanova, Ilyuza Galimullina and Lyudmila Obukhova \\ Institute of Fundamental Medicine and Biology, Kazan Federal University, 74 K. Marx Street, Kazan 420008, \\ Russia; stepmed@mail.ru (N.S.); irgalimullina@mail.ru (I.G.); 29051980ludmila@mail.ru (L.O.) \\ * Correspondence: isuryana@mail.ru; Tel.: +7-917-900-9456 \\ + Presented at the 1st International Electronic Conference on Environmental Health Sciences, \\ 15 November-7 December 2018; Available online: https://iecehs-1.sciforum.net/.
}

Published: 14 November 2018

\begin{abstract}
The analysis of the intake of chemicals such as cadmium (Cd), lead (Pb), arsenic (As), and mercury $(\mathrm{Hg})$ in the diet of children aged 3-6 years from the city of Kazan for the periods 2007-2010 and 2011-2014 was carried out. The study of actual child nutrition was performed by questionnaire and time-weight methods. The calculation of daily doses was made with the account of regional exposure factors at the 95th percentile level. The non-carcinogenic risk from the exposure to methylmercury with basic food groups at the level of the 95th perc made 3.89 and 3.33 for both periods, 10.67-for arsenic in the first period, being unacceptable (hazard quotient $(\mathrm{HQ})>$ 1). In 2007-2010, the central nervous system (CNS), the hormone system (HS), the immune system (IS), and the development (hazard index $(\mathrm{HI})=15.75,12.87,11.72$, and 4.03 ) were exposed to the highest toxic effect, and in 2011-2014, the CNS and the development ( $\mathrm{HI}=4.02$ and 3.98). The risk of developing non-carcinogenic effects for these systems $(64 \%-91 \%)$ was mainly due to contamination of foods with As for the first period, and to the intake of $\mathrm{Pb}(46 \%-57 \%)$ for the second period. The value of the total individual carcinogenic risk (ICR Cd, $\mathrm{Pb}, \mathrm{As}$ ), for the second period $1.69 \times 10^{5}$ corresponded to the maximum allowable level. In 2007-2010, the total ICR was $2.45 \times 10^{4}$ which is an unacceptable level for the general population. The major contribution to the total ICR due to the intake of contaminated foods was made by As (92.55\%) in the first period, and by $\mathrm{Cd}(79.93 \%)$ in the second period. The peculiarities of the child body (the amount of chemicals ingested per kilogram of body weight is higher in children than in adults) determine the potential risk and are responsible for high vulnerability on exposure to chemicals and the development of adverse effects.
\end{abstract}

Keywords: chemical contaminants; foods; non-carcinogenic and carcinogenic risk assessment; the child population

\section{Introduction}

Modern data show that exposure to toxic metals remains a serious problem for public health. A considerable number of the population of the Russian Federation and Europe are exposed to $\mathrm{Pb}$ and $\mathrm{Cd}$ at levels higher than national reference values. Depending on conditions, from $30 \%$ to $80 \%$ of potentially harmful substances including heavy metals (HMs) enter the human body with foods. Entering the human body primarily with foods, HMs cause the disorganization of metabolic processes and functional impairment of the immune and other systems. Moreover, the determination of regional (local) exposure levels taking into account age differences in exposure 
factors, sensitivity to carcinogens [1], and the complex of ecological factors in the territory under study remains an important aspect [2,3].

\section{Materials and Methods}

We analyzed actual nutritional patterns for children aged between 3 and 6 years, in two basic directions: individual and family dietary patterns (questionnaire method), and dietary patterns in institutions where children are fed according to either full or partial meal plans (time-weight method). The actual nutritional pattern of children in the Municipal Preschool Educational Institution No. 146 in the city of Kazan was identified by analyzing monthly reports on food expenditures (according to cumulative records), as well as selectively according to menu production records. The assessment of children's nutrition was supplemented by the results of a survey of parents through questionnaires related to food intake on weekends and on weekday evenings. The assessment of exposure to $\mathrm{Hg}$ acquired from food was carried out for the period from 2011 to 2014 on the basis of the median and the 95th percentile, in accordance with Guidelines 2.3.7.2519-09 "Exposure determination and risk assessment of the impact of chemical contaminants in food on the population". The non-carcinogenic risk was assessed on the basis of studies of Hg content in food groups, performed at the accredited laboratory of the FSFHI "Center for Hygiene and Epidemiology in the Republic of Tatarstan", according to Guidelines P 2.1.10.1920-04 [4]. A characteristic of the total toxic effects was made based on hazard quotients (HQs) of the studied substances and total hazard indices (HIs) for the substances with unidirectional mechanism of action [5]. According to the European Food Safety Authority (EFSA), the tolerable weekly intake (TWI) for methylmercury (MeHg) should not exceed $1.3 \mu \mathrm{g} / \mathrm{kg}$ of body weight per week [6].

To assess the carcinogenic risk, the life time average daily doses (LADDs), the factors of carcinogenic potential (SFos), and age-dependent adjustment factors (ADAFs) were used [4].

Officially recommended data on reference (safe) concentrations (RfDs) for non-carcinogenic risk on chronic impact on the critical organs and the human body systems were applied as risk assessment criteria of the examined chemicals ingested with foods for the health of the adult and child populations (Table 1).

Table 1. Indices of non-carcinogenic and carcinogenic hazards of examined chemicals ingested via the peroral route.

\begin{tabular}{|c|c|c|c|c|c|c|}
\hline & \multirow[b]{2}{*}{ Substance } & \multicolumn{2}{|c|}{ Non-Carcinogenic Effect } & \multicolumn{2}{|c|}{ Carcinogenic Effect } & \multirow[b]{2}{*}{ Sources of Data } \\
\hline & & $\begin{array}{l}\mathrm{RfD}^{\mathrm{d}} \\
\mathrm{mg} / \mathrm{kg}\end{array}$ & $\begin{array}{c}\text { Critical Systems and } \\
\text { Organs }\end{array}$ & $\begin{array}{c}\text { SFo }{ }^{\mathrm{i}} \mathrm{mg} / \\
(\mathrm{kg} \times 24 \mathrm{~h})^{-1}\end{array}$ & $\begin{array}{l}\text { IARC f } \\
\text { Classif } \\
\text { ication }\end{array}$ & \\
\hline $\begin{array}{c}7439-92 \\
-1\end{array}$ & Lead $(\mathrm{Pb})$ & $0.035^{*}$ & $\begin{array}{l}\text { The CNS a, the } \\
\text { nervous system, the } \\
\text { blood, development, } \\
\text { the reproductive, and } \\
\text { the hormone systems }\end{array}$ & $8.5 \times 10^{3}$ & $\mathrm{~B}_{2}$ & $\begin{array}{l}\text { P.2.1.10.1920-04* } \\
\text { CALEPA }\end{array}$ \\
\hline $\begin{array}{c}7440-43 \\
-9\end{array}$ & Cadmium (Cd) & 0.001 & $\begin{array}{l}\text { The kidneys and the } \\
\text { hormone system }\end{array}$ & 0.38 & $\mathrm{~B}_{1}$ & $\begin{array}{c}\text { IRIS } \\
\text { P.2.1.10.1920-04 }\end{array}$ \\
\hline $\begin{array}{c}7440-38 \\
-2\end{array}$ & Arsenic (As) & 0.0003 & $\begin{array}{l}\text { The CNS, the nervous } \\
\text { system, the CVS c, the } \\
\text { immune and the } \\
\text { hormone systems, GIT } \\
\text { b, the skin }\end{array}$ & 1.5 & A & IRIS \\
\hline \multirow[t]{2}{*}{$\begin{array}{c}7439-97 \\
-6\end{array}$} & Mercury (Hg) & 0.0003 & $\begin{array}{l}\text { The immune system, } \\
\text { the kidneys, the CNS, } \\
\text { and the reproductive } \\
\text { and hormone systems }\end{array}$ & - & - & $\begin{array}{l}\text { P.2.1.10.1920-04; } \\
\text { WHO UNEP } 2008\end{array}$ \\
\hline & $\begin{array}{l}\text { Methylmercury } \\
\text { (MeHg) }\end{array}$ & 0.0001 & $\begin{array}{l}\text { The CNS, the kidneys, } \\
\text { the nervous system }\end{array}$ & - & - & WHO UNEP 2008 \\
\hline
\end{tabular}


a CNS-central nervous system b GIT-gastrointestinal tract; c CVS-cardiovascular system; d $\mathrm{RfD}$-reference (safe) concentration; i SFo-factor of carcinogenic potential; f IARC-International Agency for Research on Cancer.

\section{Results and Discussion}

The amount of imported products reduced considerably due to the imposition of sanctions, and recently local food products gained great importance among the population of the Republic of Tatarstan. The specific gravity of food samples exceeding the hygienic normative in the content of chemical contaminants made $0.5 \%$ in 2014 (0.2\% in 2013), but at the same time it remains lower than in the Russian Federation as a whole (0.6\% in 2013 and $0.7 \%$ in 2012).

Our studies showed that for both periods the ingestion of $\mathrm{Pb}$ with foods at $\mathrm{Me}$ and 95th percentile levels respectively $(82.14 \%$ and $85.91 \% ; 86.77 \%$ and $87.77 \%)$ made a major contribution to the total exposure for adults and children. $\mathrm{Cd}(16.21 \%$ and $12.47 \%$ at Me level; $10.88 \%$ and 10.04 at the level of the 95th percentile) and As (14.19\% in Me and 34.35\% at 95th percentile) ranked second in the total exposure for the period 2007-2010. The exposure value for the ingestion of contaminants with foods was found to be 1.44 times higher in Me in the second period, and 1.13 times higher at the 95th percentile in the first period (Table 2).

Table 2. Results of exposure (intake) assessment of chemical contaminants with foods.

\begin{tabular}{|c|c|c|c|c|c|c|c|c|}
\hline \multirow{3}{*}{ Contaminants } & \multicolumn{4}{|c|}{ 2007-2010 Years } & \multicolumn{4}{|c|}{ 2011-2014 Years } \\
\hline & \multicolumn{2}{|c|}{$\begin{array}{c}\text { Exposure } \\
\left(\mu \mathrm{g}(\mathrm{kg} / 24 \mathrm{~h})^{(-1)} \text { day }\right)\end{array}$} & \multicolumn{2}{|r|}{$\%$} & \multicolumn{2}{|c|}{$\begin{array}{c}\text { Exposure } \\
\left(\mu \mathrm{g}(\mathrm{kg} / 24 \mathrm{~h})^{(-1)} \text { day }\right)\end{array}$} & \multicolumn{2}{|r|}{$\%$} \\
\hline & Me & $\begin{array}{l}\text { 95th } \\
\text { perc }\end{array}$ & Me & 95th perc & Me & $\begin{array}{l}\text { 95th } \\
\text { perc }\end{array}$ & Me & 95th perc \\
\hline Lead & 0.00952 & 0.03329 & 69.64 & 51.02 & 0.01694 & 0.05072 & 85.91 & 87.77 \\
\hline Cadmium & 0.00154 & 0.00710 & 11.27 & 10.88 & 0.00246 & 0.00580 & 12.47 & 10.04 \\
\hline Arsenic & 0.00194 & 0.02241 & 14.19 & 34.35 & 0.00006 & 0.00008 & 0.3 & 0.01 \\
\hline Mercury & 0.00055 & 0.00218 & 4.02 & 3.34 & 0.00016 & 0.00093 & 0.81 & 1.61 \\
\hline Methylmercury & 0.00012 & 0.00027 & 0.88 & 0.41 & 0.00010 & 0.00033 & 0.51 & 0.57 \\
\hline Total & 0.01367 & 0.06525 & 100 & 100 & 0,01972 & 0.05778 & 100 & 100 \\
\hline
\end{tabular}

The major proportion of $\mathrm{Pb}$ contribution to the total exposure was made by cereals and bakery goods $(21.56 \%$ and $31.63 \%$ at Me level; $24.02 \%$ and $35.02 \%$ at the level of 95th percentile); meat and meat products, poultry, and eggs $(24.17 \%$ and $30.22 \%$ at Me level; $18.18 \%$ and $22.58 \%$ at the level of 95th percentile); and milk and dairy products $(31.14 \%$ and $18.94 \%$ at Me level; $33.78 \%$ and $20.42 \%$ at the level of 95th percentile) for children.

The groups of food products which contributed most to $\mathrm{Cd}$ exposure for both periods were grains, cereals, and bakery goods $(42.63 \%$ and $17.82 \%$ at Me level, and $39.81 \%$ and $40.17 \%$, at the level of 95th percentile); and for the period 2011-2014, milk and dairy products (64.57\% at Me level; and $27.35 \%$ at the level of 95 th percentile), as well as cereals and bakery goods ( $8.93 \%$ and $17.82 \%$ for children at Me level; and $24.34 \%$ and $40.17 \%$, at the level of 95th percentile). Meat and meat products, poultry, meat, and eggs $(28.78 \%$ and $36.86 \%$ at Me level; $20.73 \%$ and $28.84 \%$ at the level of 95th percentile respectively), cereals and bakery goods ( $28.52 \%$ and $18.45 \%$ at Me level; and $40.49 \%$ and $42.74 \%$ at the level of 95th percentile) comprised the major contribution to Hg exposure. Fish and non-finfish $(18.55 \%$ and $28.79 \%$ at Me level, $10.94 \%$ and $19.80 \%$ at the level of 95 th percentile) ranked second in order of importance of $\mathrm{Hg}$ ingestion with foods in children.

The major contribution to the total value of As exposure for the period 2007-2010 was made by fish and non-finfish (83.13\% at Me level, $77.44 \%$ at the level of 95th percentile); for the period 2011-2014, milk and dairy products $(57.78 \%$ at Me level; and $64.37 \%$ at the level of 95 th percentile), and sugar and confectionery goods ( $42.22 \%$ at Me level; and $35.63 \%$ at the level of 95 th percentile). In the other product groups, the content of As was not discovered. 
In aquatic ecosystems, mercury transforms into its organic form, methylmercury (MeHg), which is more bioavailable and bioaccumulates in water food chains to reach the highest concentrations at the upper trophic levels. $\mathrm{MeHg}$ is the dominant form of mercury found in fish and other seafoods, and it is particularly toxic for the developing nervous system, including the brain. According to recommendations of the United Nations Environment Programme (UNEP) and the WHO, a recalculation of $\mathrm{Hg}$ in fish and non-finfish to $\mathrm{MeHg}$ was made in 2008. It should be noted that inorganic mercury is a food pollutant, but its impact is considered less important because of its lower toxicity compared with methylmercury [7-10].

The risk characteristics showed that the levels of non-carcinogenic (HQ) from exposure to $\mathrm{Pb}$, $\mathrm{Cd}$, As, and $\mathrm{Hg}$ in the years 2007-2010 (0.039-0.260 at Me level), and in the years 2011-2014 (0.029-0.351 at Me level; 0.039-0.829 at the level of the 95th percentile) did not exceed the reference value equal to 1.0. The increased value of the $\mathrm{MeHg}$ content in fish and seafoods, at the level of 95th percentile, for children was responsible for an average risk level $(\mathrm{HQ}=2.67-2.29)$, and as for As, the risk level was extremely high $(\mathrm{HQ}=10.67)$.

The total hazard indices (HI), calculated on the basis of Me, were below 3.0 (2.68 in the first and 1.19 in the second periods, which indicates an allowable risk. The alarming level of non-carcinogenic risk $(\mathrm{HI}=3.81)$ was determined at the level of 95th percentile in children in the second period, and in the first period it was extremely high $(\mathrm{HI}=15.53)$.

The examined chemical contaminants $(\mathrm{Pb}, \mathrm{Cd}, \mathrm{As}, \mathrm{Hg}$, and $\mathrm{MeHg})$ found in the analyzed groups of foods during the period under study have the potential to cause various harmful effects in the human body [11].

In the period 2007-2010, the major contribution to the total hazard index (HI) caused by contamination of all examined foods in Me and 95th percentile was made by As (34.54\% and $68.72 \%$ respectively), and $\mathrm{MeHg}$ ( $46.32 \%$ and $17.2 \%$ respectively).

The contribution of $\mathrm{Cd}, \mathrm{Pb}$, and $\mathrm{Hg}$ ranged from $1.45 \%$ to $9.69 \%$ in $\mathrm{Me}$, and from $0.88 \%$ to $6.67 \%$ in 95 th percentile. In the period 2011-2014, for the child population, the major contribution to $\mathrm{HI}$ in $\mathrm{Me}$ and 95 th percentile was made by $\mathrm{MeHg}(55.65 \%$ and $60.16 \%$ respectively) and $\mathrm{Cd}(29.57 \%$ and $21.77 \%$ respectively), the contribution of $\mathrm{As}, \mathrm{Pb}$, and $\mathrm{Hg}$ made from $2.4 \%$ to $6.57 \%$ in $\mathrm{Me}$ and from $1.02 \%$ to $11.61 \%$ in the 95th percentile. Besides this, there was an alarming level of non-carcinogenic risk for the genitourinary system $(\mathrm{HI}=3.56-5.78)$ and the central nervous system $(\mathrm{HI}=3.0-7.92)$ at the level of the 95th percentile in children for both periods. The risk of developing non-carcinogenic effects for the organs of the genitourinary and the central nervous system was primarily due to contamination of foods with $\mathrm{MeHg}$ (60.73\% and $76.32 \%$ respectively) (Table 3 ).

Table 3. Risk assessment of lesions in critical organs and body systems of the child population of the city of Kazan on the development of non-carcinogenic effects due to the chemical contamination of foods.

\begin{tabular}{|c|c|c|c|c|c|c|c|c|c|}
\hline \multirow{3}{*}{$\begin{array}{c}\text { Critical } \\
\text { Organs } \\
\text { And } \\
\text { Body } \\
\text { Systems }\end{array}$} & \multirow{3}{*}{$\begin{array}{c}\text { Contaminants } \\
\text { Determining } \\
\text { the Effect }\end{array}$} & \multicolumn{4}{|c|}{$2007-2010$} & \multicolumn{4}{|c|}{ 2011-2014 } \\
\hline & & \multicolumn{2}{|c|}{ Hazard Index (HI) } & \multicolumn{2}{|c|}{$\begin{array}{l}\text { Contribution of } \\
\text { Organs and } \\
\text { Systems to } \\
\Sigma H I(\%)\end{array}$} & \multicolumn{2}{|c|}{ Hazard Index (HI) } & \multicolumn{2}{|c|}{$\begin{array}{l}\text { Contribution of } \\
\text { Organs and } \\
\text { Systems to } \\
\Sigma \text { HI (\%) }\end{array}$} \\
\hline & & Me & 95th perc & Me & 95th perc & Me & 95th perc & Me & 95th perc \\
\hline Kidneys & $\mathrm{Cd}, \mathrm{Hg}, \mathrm{MeHg}$ & 3.03 & 5.78 & 20.32 & 18.24 & 1.09 & 3.56 & 29.86 & 29.16 \\
\hline $\begin{array}{l}\text { Hormone } \\
\text { system }\end{array}$ & $\mathrm{Cd}, \mathrm{Pb}, \mathrm{As}, \mathrm{Hg}$ & 1.66 & 3.93 & 11.13 & 12.4 & 0.53 & 1.52 & 14.52 & 12.45 \\
\hline CNS & $\mathrm{Pb}, \mathrm{As}, \mathrm{Hg}, \mathrm{MeHg}$ & 3.85 & 7.92 & 25.82 & 24.99 & 0.84 & 3.00 & 23.01 & 24.57 \\
\hline $\begin{array}{l}\text { Nervous } \\
\text { system }\end{array}$ & $\mathrm{Pb}, \mathrm{As}, \mathrm{MeHg}$ & 3.71 & 7.88 & 24.88 & 24.87 & 0.76 & 2.54 & 20.82 & 20.80 \\
\hline CVS & As & 1.13 & 2.93 & 7.58 & 9.25 & 0.03 & 0.04 & 0.82 & 0.33 \\
\hline Blood & $\mathrm{Pb}$ & 0.04 & 0.08 & 0.27 & 0.25 & 0.07 & 0.21 & 1.92 & 1.72 \\
\hline $\begin{array}{c}\text { Reproductive } \\
\text { system }\end{array}$ & $\mathrm{Pb} \mathrm{Hg}$ & 0.18 & 0.12 & 1.21 & 0.38 & 0.15 & 0.65 & 4.11 & 5.32 \\
\hline $\begin{array}{l}\text { Immune } \\
\text { system }\end{array}$ & As, $\mathrm{Hg}$ & 1.27 & 2.97 & 8.52 & 9.37 & 0.11 & 0.48 & 3.02 & 3.93 \\
\hline Development & $\mathrm{Pb}$ & 0.04 & 0.08 & 0.27 & 0.25 & 0.07 & 0.21 & 1.92 & 1.72 \\
\hline Total & & 14.91 & 31.69 & 100 & 100 & 3.65 & 12.21 & 100 & 100 \\
\hline
\end{tabular}


The examined contaminants $(\mathrm{Pb}, \mathrm{Cd}, \mathrm{As})$ are potential chemical carcinogens belonging to groups A, B1, and B2 according to International Agency for Research on Cancer (IARC) classification [4]. The results of calculating the individual (ICR) and population (PCR) carcinogenic risks for the population health caused by contamination of foods with $\mathrm{Pb}, \mathrm{Cd}$, and As are given in Table 4. According to the United States Environmental Protection Agency (US EPA), carcinogenic risks are overall higher on exposures during early life periods compared with similar exposures at older ages. An ADAF equal to 3 at the ages from 2 to 16 years old was used for the quantitative assessment of the carcinogenic potential of chemicals with genotoxic effect $(\mathrm{Pb}, \mathrm{Cd})$ [12].

Table 4. Indices of carcinogenic risk for the health of the child population due to contamination of foods with chemicals. ICR: individual carcinogenic risk; PCR: population carcinogenic risk.

\begin{tabular}{|c|c|c|c|c|c|c|}
\hline Contaminants & $\begin{array}{l}\text { Slope factor } \\
\text { (SFo) }\end{array}$ & & Years & $\Sigma$ LADD & ICR & PCR \\
\hline \multirow{4}{*}{$\mathrm{Pb}$} & \multirow{4}{*}{0.0085} & \multirow{2}{*}{$\mathrm{Me}$} & $2007-2010$ & $1.75 \times 10^{4}$ & $1.49 \times 10^{6}$ & 1.0 \\
\hline & & & 2011-2014 & $3.11 \times 10^{4}$ & $2.64 \times 10^{6}$ & 0.2 \\
\hline & & \multirow{2}{*}{ 95th perc } & $2007-2010$ & $6.11 \times 10^{4}$ & $5.20 \times 10^{6}$ & 0.3 \\
\hline & & & 2011-2014 & $9.31 \times 10^{4}$ & $7.92 \times 10^{6}$ & 0.5 \\
\hline \multirow{4}{*}{$\mathrm{Cd}$} & \multirow{4}{*}{0.38} & \multirow{2}{*}{$\mathrm{Me}$} & $2007-2010$ & $2.83 \times 10^{4}$ & $1.07 \times 10^{5}$ & 0.7 \\
\hline & & & 2011-2014 & $4.51 \times 10^{4}$ & $1.72 \times 10^{5}$ & 1.0 \\
\hline & & \multirow{2}{*}{ 95th perc } & $2007-2010$ & $1.30 \times 10^{4}$ & $4.95 \times 10^{5}$ & 3.0 \\
\hline & & & 2011-2014 & $1.07 \times 10^{4}$ & $4.05 \times 10^{5}$ & 2.5 \\
\hline \multirow{4}{*}{ As } & \multirow{4}{*}{1.5} & \multirow{2}{*}{$\mathrm{Me}$} & $2007-2010$ & $3.96 \times 10^{4}$ & $5.93 \times 10^{5}$ & 3.7 \\
\hline & & & 2011-2014 & $3.70 \times 10^{4}$ & $5.56 \times 10^{7}$ & 0.03 \\
\hline & & \multirow[b]{2}{*}{ 95th perc } & $2007-2010$ & $4.54 \times 10^{4}$ & $6.80 \times 10^{4}$ & 42.0 \\
\hline & & & 2011-2014 & $4.99 \times 10^{4}$ & $7.48 \times 10^{7}$ & 0.04 \\
\hline
\end{tabular}

The values of total individual carcinogenic risk $(\mathrm{ICR} \mathrm{Cd}, \mathrm{Pb}, \mathrm{As})$ both in the first $\left(7.16 \times 10^{5}\right)$ in $\mathrm{Me}$, and in the second period $\left(2.03 \times 10^{5}\right.$ in Me and $4.92 \times 10^{5}$ in 95 th percentile $)$ were within the range of allowable values. That is, they corresponded to the upper limit of acceptable risk. These levels of individual carcinogenic risk to the population must be constantly controlled. In the period 2007-2010, total individual carcinogenic risk in 95th percentile reached $7.35 \times 10^{4}$, which is unacceptable for the general population and requires that risk minimization activities be carried out.

The major contribution to total ICR due to consumption of contaminated foods was made by $\mathrm{Cd}(82.37 \%-89.73 \%)$ and $\mathrm{Pb}(10.17 \%-16.11 \%)$. The value of population carcinogenic risk (PCR Cd, $\mathrm{Pb}, \mathrm{As}$ ) implies the possible appearance of up to three additional cases (in addition to the background level of cancer morbidity) of malignant neoplasms among the child population.

\section{Conclusions}

The exposure value in children upon the ingestion of contaminants with foods was found to be 1.44 times higher in Me in the second period, and 1.13 times higher in 95th percentile in the first period.

Exposure of the child population to environmental contaminants differs significantly from that in adults due to various causes associated with the children's activity, behavior and nutrition, physiological peculiarities of metabolism, permeability of the skin integuments, etc. The children's response can be modified, but it is practically impossible to predict its degree [12, 13].

The levels of non-carcinogenic risk from the exposure to $\mathrm{Pb}, \mathrm{Cd}, \mathrm{As}$, and $\mathrm{Hg}$ for the child population were allowable, because they did not exceed the reference value equal to 1.0. The increased values of $\mathrm{MeHg}$ content in fish and seafoods at the level of the 95th percentile for children were responsible for an average risk level $(\mathrm{HQ}=2.67-2.29)$. For $\mathrm{As}$, the risk level was extremely high $(\mathrm{HQ}=10.67)$. 
There was an extremely high level $(\mathrm{HI}=15.53)$ in the first period, and an alarming level of the total non-carcinogenic risk $(\mathrm{HI}=3.81)$ in children at the level of the 95th percentile. The critical systems exposed to the highest toxic effect was in the case of simultaneous exposure to the examined chemicals. The individual carcinogenic risk (ICR) was assessed as negligibly small due to the content of $\mathrm{Pb}$ and $\mathrm{Cd}$ in foods for the child population. It requires no additional activities for its decrease and is subject to selective periodical control. In the period 2007-2010, the value of the total individual carcinogenic risk (ICR, As) was $7.35 \times 10^{4}-95$ th percentile, which is unacceptable for the general population and requires that risk minimization activities be carried out, and must be constantly controlled.

The results of our studies showed higher risks of exposure of children aged 3-6 years to the chemicals ingested with foods. The risk assessment is usually associated with uncertainty at the stages of exposure assessment. In our case, we tried to mitigate this aspect, and this increased the accuracy and reliability of the risk being assessed. Such exposure factors as the amount of water and the consumption of various foods should be corrected when specific regional peculiarities are available. Thus, the regional exposure factors (i.e., the body weight) identified in a cross-sectional study of the Kazan Federal University (KFU) employees were used, and the peculiarities of individual and family nutrition at the regional level were taken into account during calculations, because the greater part of the population (up to $95 \%$ ) consume locally produced food. The use of age-specific sensitivity to carcinogens with the application of ADAF to substances with genotoxic effect allowed a correct assessment of carcinogenic risk to be performed. The obtained results of carcinogenic risks for adults and children had no significant differences, this being possibly related with the absence of data on contamination with As for the period under study. However, we showed that on peroral ingestion of chemicals with drinking water, the level of carcinogenic risk calculated taking into the ADAF account exceeded the risk levels calculated without age-specific rates of sensitivity to carcinogens by a factor of 2-3 [11].

At the same time, the amount of certain HMs getting into the human body depends not only on one's consumption of foods containing a specific element, but to a great extent on the quality of one's diet as well. For instance, even insignificant iron deficiency considerably enhances the accumulation of cadmium [10]. According to our data, during the past 10 years, the prevalence of anemia among children from 0 to 14 years old in the city of Kazan made up to $95 \%$ of the class of diseases of the blood and blood-forming organs and certain disorders involving the immune mechanism [14,15]. The findings of this study significantly contribute to the field of food safety, considering the health risk for child population in the city of Kazan. The account of regional (local) peculiarities is of great importance during the pollution control of foods, because HMs can serve as irreplaceable microelements or as toxicants. Currently, the regional risk assessment reflecting the full range and specific peculiarities of the populations under study and accepted exposure scenarios has great importance, and is of great practical importance when developing risk minimization activities.

Acknowledgments: This work was funded by the subsidy allocated to Kazan Federal University for the state assignment in the sphere of scientific activities 19.9777.2017/8.9.

Conflicts of Interest: The authors declare no conflict of interest.

\section{References}

1. Prüss-Ustün, A.; Vickers, C.; Haefliger, P.; Bertollini, R. Knowns and unknowns on burden of disease due to chemicals: a systematic review. Environ. Health 2011, 10, 9-24. Available online: https://ehjournal.biomedcentral.com/articles/10.1186/1476-069X-10-9 (accessed on 8 November 2018).

2. Rakhmanin, Y.A.; Novikov, S.M.; Avaliani, S.L.; Sinitsyna, O.O.; Shashina, T.A. Actual problems of environmental factors risk assessment on human health and ways to improve it. Health Risk Anal. 2015, 2, 4-11.

3. Stepanova, N.V.; Valeeva, E.R.; Fomina, S.F. Assessment of the total exposure to heavy metals of the child population city of Kazan. Gig Sanit 2015, 5, 56-61.

4. Guidelines for Health Risk Assessment for the Population on Exposure to Chemical Substances Polluting the Environment; Federal Center of the State Committee for Sanitary and Epidemiological Control: Moscow, Russia, 2004; p. 143. 
5. Avaliani, S.L.; Novikov, S.M.; Shashina, T.A.; Kislitsin, V.A.; Skvortsova, N.S. Experience of use of methodology of an assessment of risk to population health for ensuring sanitary and epidemiologic wellbeing: In Works of the All-Russian Scientific and Practical Conference with the International Participation; RIO ATA: Angarsk, Russia, 2012; pp. 12-16.

6. UNEP DTIE Chemicals Branch and WHO Department of Food Safety, Zoonoses and Foodborne Diseases. Guidance for Identifying Populations at Risk from Mercury Exposure; WHO: Geneva, Switzerland, 2008.

7. Buchanan, S.; Anglen, J.; Turyk, M. Methyl mercury exposure in populations at risk: Analysis of NHANES 2011-2012. Environ. Res. 2015, 140, 56-64. Available online: http: //www.sciencedirect.com/ science/article/pii/S0013935115000766 (accessed on 8 October 2018).

8. Mason, R.P.; Choi, A.L.; Fitzgerald, W.F.; Hammerschmidt, C.R.; Lamborg, C.H.; Soerensen, A.L.; Sunderland, E.M. Mercury biogeochemical cycling in the ocean and policy implication. Environ. Res. 2012, 119, 101-107.

9. Sirot, V.; Guerin, T.; Mauras, Y.; Garraud, H.; Volatier, J.-L.; Leblanc, J.-Ch. Methyl mercury exposure assessment using dietary and biomarker data among frequent seafood consumers in France: CALIPSO study. Eighth International Conference on Mercury as a Global Pollutant: Human Health and Exposure to Methylmercury. 2008; Volume 107, pp. 30-38. Available online: http://www.sciencedirect.com/ science/article/pii/ S0013935107002484 (accessed on 28 August 2018).

10. Dietary exposure to inorganic arsenic in the European population. European Food Safety Authority. EFSA, 2014; volume 12, doi:10.2903/j.efsa.2014.3597. Available online: http://onlinelibrary.wiley.com/ doi/10.2903/j.efsa.2014.3597/references (accessed on 15 August 2018).

11. Stepanova, N.V.; Fomina, S.F.; Yusupova, N.Z.; Khairullina, L.R. Risk Assessment and Age Sensitivity to Chemicals from Drinking Water. Innovations in Technical and Natural Sciences; Monograph ed.; Busch, P., Ed.; East West Association for Advanced Studies and Higher Education GmbH: Vienna, Austria, 2017; Volume 4, pp. 65-77.

12. Unguryanu, T.N.; Novikov, S.M. Results of health risk assessment due to exposure to contaminants in drinking water in Russia population (review of literature). Gig Sanit 2014, 1, 19-24.

13. Stepanova, N.V.; Arkhipova, N.S.; Fomina, S.F. Priority chemical pollutants of drinking water in the city of Kazan: approach based on risk assessment. IOP Conf. Ser. Earth Environ. Sci. 2017, 107, 1-5.

14. Unguryanu, T.N. Hygienic assessment of food quality in the city of Novodvinsk. Hum. Ecology j. 2010, 12, $10-17$.

15. Stepanova, N.V.; Valeeva, E.R. Main trends in children's population health in the republic of tatarstan. Gig Sanit 2015, 1, 92-97.

(C) 2018 by the authors. Licensee MDPI, Basel, Switzerland. This article is an open access article distributed under the terms and conditions of the Creative Commons Attribution (CC BY) license (http://creativecommons.org/licenses/by/4.0/). 